\title{
Ventilatory mechanics in patients with bronchiectasis starting in childhood
}

\author{
L. I. LA N D A U ${ }^{1}$, P. D. PHELAN and H. E. W ILLIAMS \\ Clinical Research Unit, Royal Children's Hospital Research Foundation, Parkville, Australia
}

\begin{abstract}
Landau, L. I., Phelan, P. D., and Williams, H. E. (1974). Thorax, 29, 304-312. Ventilatory mechanics in patients with bronchiectasis starting in childhood. The mechanics of ventilation have been studied in 69 children and young adults with bronchiectasis since childhood. Many were well with little disability and although symptoms had ameliorated in the second decade cough and sputum still persisted.

This study suggests that many patients had generalized small airway disease, as demonstrated by abnormal maximum expiratory flow volume curves together with increased lung volumes and frequency dependence of dynamic compliance. A group of patients was found in whom compliant airways in the bronchiectatic segment may have been contributing to 'slow space' emptying and air trapping.

Postoperative function in those treated surgically related to the extent of persisting disease rather than to the resection itself. In the absence of persisting disease there were no significant changes in lung volumes or elastic recoil after resection of one or two lobes in childhood.
\end{abstract}

Very few studies have been done on the mechanics of ventilation in young patients with bronchiectasis. The findings reported include reduced maximum mid-expiratory flow, elevated pulmonary resistance, and reduced dynamic compliance (Cherniak and Carton, 1966; Pande, Jain, Gupta, and Guleria, 1971). However, tests that assess the presence of small airway obstruction and define accurately the elastic recoil have not been performed.

Similarly, there have been very few reports of pulmonary mechanics after lung resection in these patients. Lung volumes have been reported to be greater than predicted for the amount of remaining lung tissue but less than predicted for two lungs (Lester, Cournand, and Riley, 1942; Birath, Crafoord, and Rudström, 1947; Peters et al., 1950; Filler, Gomez, and Stone, 1966). Dynamic compliance was also found to be low (McIlroy and Bates, 1956; Kamener, Becklake, Goldman, and McGregor, 1958) although the distribution of ventilation was usually normal. Studies to determine elastic recoil and tests for the presence of persisting small airway disease

'In receipt of National Health and Medical Research Council Fellowship have not been done in patients who had lung resections in childhood.

The present study was carried out to determine pulmonary mechanics in young people with bronchiectasis. Tests were performed to detect the presence and severity of expiratory flow limitation, as well as to define the relative contributions to this reduced flow of small airway obstruction, large airway disease, and changes in elastic recoil. The effect of lung resections in childhood on the pulmonary mechanics of patients with bronchiectasis was also assessed.

\section{MATERIALS AND METHODS}

Sixty-nine patients with bronchiectasis proven at bronchography were studied; their age range is shown $\mathrm{W}$ in Table I. Letters had been sent to a total of $178 \underset{\gamma}{\sigma}$

T A B L E I

AGE DISTRIBUTION OF PATIENTS STUDIED

\begin{tabular}{c|c}
\hline $\begin{array}{c}\text { Age } \\
\text { (years) }\end{array}$ & No. of Patients \\
\hline$<10$ & 1 \\
$10-15$ & 5 \\
$15-20$ & 16 \\
$20-25$ & 35 \\
$25-30$ & 9 \\
$>30$ & 3 \\
\hline
\end{tabular}


patients with bronchiectasis seen at the Royal Children's Hospital, Melbourne from 1940 onwards. Seventy-two patients agreed to come in and perform the pulmonary function tests and were able to cooperate with the manoeuvres. Two studies were unsatisfactory and one patient with a large shunt due to an atrial septal defect was excluded. Of the other patients, two replied that they were unable to attend and 84 were not traced. None of the tests was performed immediately following bronchography and no patient had an acute respiratory infection at the time of the study.

The onset of symptoms was before 2 years of age in 46 patients and between 2 and 6 years in another 14 patients. The underlying causes are shown in Table II. All patients were treated with antibiotics and postural drainage and 20 also had surgical resections. Those treated surgically had localized disease with significant symptoms persisting into late childhood or early adolescence, whereas those treated medically had either minimal symptoms or marked symptoms with extensive disease. Twenty-five resections were performed on 20 patients between the ages of 3 and 23 years although most were performed at about 14 years of age.

T A B L E II

UNDERLYING OR PREDISPOSING DISEASE IN PATIENTS STUDIED

\begin{tabular}{l|c}
\hline \multicolumn{1}{c|}{ Underlying Disease } & No. of Patients \\
\hline Measles & $\mathbf{8}$ \\
Pertussis & 7 \\
Pink disease & 6 \\
Pneumonia & 7 \\
Collapsed lobe & 3 \\
Scarlet fever & 1 \\
Kartegener's syndrome & 1 \\
Asthma & 1 \\
Agammaglobulinaemia & 1 \\
Insidious onset & 34 \\
\hline
\end{tabular}

Classification of a disease so variable in its aetiology and natural history is difficult, so a grouping of patients by extent of involvement is useful. To simplify clinical assessment a clinical score was used. A score of 1 to 7 was given using the following criteria: 1 , asymptomatic; 2 , intermittent cough; 3 , intermittent cough and sputum with respiratory infections only; 4, chronic non-productive cough; 5, chronic cough with less than five blobs of sputum per day; 6 , chronic cough with greater than five blobs of sputum per day; 7 , chronic cough, large volumes of sputum, and limitation of normal activity due to respiratory symptoms.

Although this score gives some indication of the symptoms of cough and sputum, it does not indicate ability to cope with normal activities, sport, and work. Many patients producing large amounts of sputum were generally well, playing sport, and missing no time from work.
The investigations performed were spirometric tests and detailed studies of mechanics of ventilation using a whole body plethysmograph.

SPIROMETRY Forced vital capacity (FVC) and forced expiratory volume in one second $\left(F E V_{1}\right)$ were measured with a 9-litre expirograph (Godart EP62001). The result was taken as the best of two or three efforts and the volumes, at BTPS, were expressed as a percentage of the predicted normal value for height and sex (Polgar and Promadhat, 1971). The lower limit of normal for $\mathrm{FEV}_{1} / \mathrm{VC}$ was taken as 72\% (Polgar and Promadhat, 1971).

LUNG VOLUMES Total lung capacity (TLC) and residual volume (RV) were measured in a flow displacement body plethysmograph (Mead, personal communication) by the gas compression technique based on Boyle's Law (Du Bois et al., 1956a). Details of the technique have been described elsewhere (Landau and Phelan, 1973). Results were expressed as a percentage of predicted normal for height and sex (Polgar and Promadhat, 1971).

MAXIMUM EXPIRATORY FLOW VOLUME (MEFV) CURVES An MEFV curve (Hyatt, Schilder, and Fry, 1958) was produced by the patient sitting in the plethysmograph and performing a forced vital capacity manoeuvre. Volume change measured in the plethsymograph was recorded on the abscissa, and flow measured at the mouth with a Fleisch No. 4 pneumotachograph coupled to a Sanborn P270 pressure transducer on the ordinate. The curve was displayed on a Tektronix 564B storage oscilloscope and photographed. An MEFV curve relates the maximum expiratory flow rate (Vmax) to lung volume at all instants during a forced vital capacity manoeuvre.

The curve was quantitated by measuring $V \max$ at a lung inflation of $50 \%$ TLC. The absolute Vmax was divided by TLC and expressed as a fraction of a $\mathrm{TLC} / \mathrm{sec}$, thus allowing lungs of different size to be compared (Zapletal et al., 1969). A lower limit of normal established in this laboratory for Vmax at $50 \%$ TLC was found to be in agreement with that reported by Zapletal and co-workers (1969) and is $0.41 \mathrm{TLC} / \mathrm{sec}$. Increasing obstruction was demonstrated by increasing convexity of the curve to the abscissa and by a fall in the absolute level of Vmax. Figure 1 demonstrates the patterns of MEFV curves seen.

RESPIRATORY RESISTANCE Respiratory resistance (Rresp) was measured using the technique of forced oscillation originally described by $\mathrm{Du}$ Bois, Brody, Lewis, and Burgess (1956b). In the present study measurements were made at $4 \mathrm{~Hz}$ and resonance was simulated by subtracting a signal proportional to volume from the pressure signal until looping of the pressure flow relationship was at a minimum (Grimby et al., 1968). 


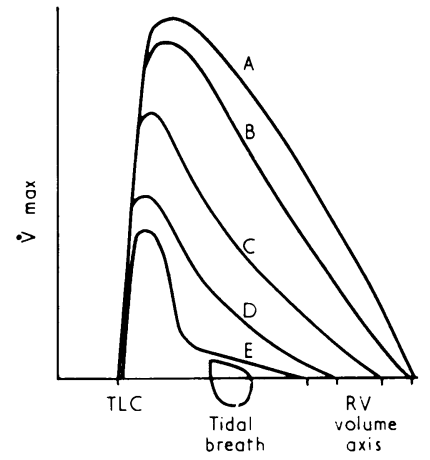

FIG. 1. Combined representation of patterns of MEFV curves obtained: (A) descending limb straight or slightly concave to $x$-axis; (B) minimal convexity to $x$-axis low in the $V C$; (C) mild uniform convexity to $x$-axis; (D) moderate convexity to $x$-axis, usually associated with reduced $\dot{V} \max$ and low VC; (E) marked convexity to $x$-axis often biphasic. Tidal breathing is on $M E F V$ curve.

Airways smaller than about $2.0 \mathrm{~mm}$ in diameter (i.e., from bronchioles peripherally) contribute a relatively minor part of the total airways resistance (Macklem and Mead, 1967) and consequently substantial changes must occur in them before measurements of resistance are significantly altered. A normal measurement means only that the larger airways are not significantly narrowed. In the present study measurement of Rresp was used to identify patients in whom there was no significant narrowing of larger airways during tidal breathing. This would seem to be the main value of any measurement of Rresp using the technique of forced oscillation (Landau and Phelan, 1973).

STATIC RECOIL CURVES AND CONDUCTANCE OF THE UPSTREAM SEGMENT Static elastic recoil curves were measured during deflation with an oesophageal balloon following closely the method described by Milic-Emili, Mead, Turner, and Glauser (1964). Transpulmonary pressure was measured with a Statham PM 131TC differential pressure transducer and lung volumes in the plethysmograph.

Normal limits for static elastic recoil curves for children, adolescents, and young adults were determined from an analysis of the data of Turner, Mead, and Wohl (1968) and Wohl and Mead (personal communication).

Conductance of the upstream segment (Gus) at a given lung volume is the ratio of Vmax to static recoil pressure at that volume (Mead, Turner, Macklem, and Little, 1967). The upstream segment is a zone derived from the concept of the equal pressure point (EPP), which is the point along the airways during a forced expiration at which the external pressure (pleural pressure) is equal to the lateral intrabronchial pressure. The upstream segment includes the airways from the alveoli to this EPP. Gus therefore provides information regarding the contribution of the smaller $\bar{\sigma}$ airways to flow limitation. In the present study Gus was measured at FRC. Above 30\% VC the lower limit of normal for Gus is $0.07 \mathrm{TLC} / \mathrm{sec}$ under 18 years of age and $0.10 \mathrm{TLC} / \mathrm{sec}$ over 18 years of age (Mead $\omega$ et al., 1967; Zapletal et al., 1969).

DYNAMIC COMPLIANCE Dynamic compliance (Cdyn) $\vec{\omega}$ was measured by relating changes in lung volume to corresponding changes in transpulmonary pressure $\times$ during tidal breathing at $20,40,60$, and 80 breaths $\mathrm{N}$ per minute, as described by Woolcock, Vincent, and $\omega$ Macklem (1969). Compliance at 40, 60, and 80 w breaths per minute was expressed as a percentage of the compliance at 20 breaths per minute, which was 윽 taken as the basal level. Frequency dependence of $\rightarrow$ Cdyn was considered present when there was a fall 3 in compliance greater than $25 \%$ and a statistically significant difference between the means $(P<0.05)$.

Cdyn becomes frequency dependent when there is $\vec{v}$ maldistribution of ventilation (Otis et al., 1956). This $\square$ can result from disturbance in either the elastic pro- $\square$ perties of the lung tissues or in the flow-resistive properties of the airways. In the presence of normal elastic recoil and normal Rresp, frequency dependence of Cdyn is likely to be the result of obstruction in $\frac{2}{\Phi}$ the smaller airways which contribute only a small $\unrhd$ amount of total Rresp. Hence the measurement of fre- $\overrightarrow{\vec{O}}$ quency dependence of Cdyn is a sensitive test for small $\frac{0}{3}$ airways disease when other tests of lung function are $\bar{Z}$ normal (Woolcock et al., 1969). Normal children and adolescents have not been shown to have frequency dependence of Cdyn when the measurement is made above FRC and at the frequencies used in this study (Macklem, 1971).

\section{RESULTS}

PRESENT CLINICAL STATUS Table III gives the present status in relation to the number of seg- 음 ments and type of treatment. The response to $\frac{D}{O}$ medical treatment bore some relation to the extent of the disease. Eighteen of 20 patients with more $\mathrm{N}$ than six segments involved had a clinical score greater than four. In the surgically treated group with extensive disease clinical scores were poor. Of 46 patients with fewer than six segments involved, those treated surgically had slightly better clinical scores, probably reflecting selection.

SPIROMETRIC TESTS The results of spirometric tests are given in Table IV. Nine patients had a reduced VC and 17 a reduced FEV/VC ratio. Eight of these had been treated surgically, and the use of predicted normal values for two lungs may not be valid, although the other surgically treated 
T A B L E III NUMBER OF SEGMENTS INVOLVED AND TREATMENT RELATED TO PRESENT STATUS

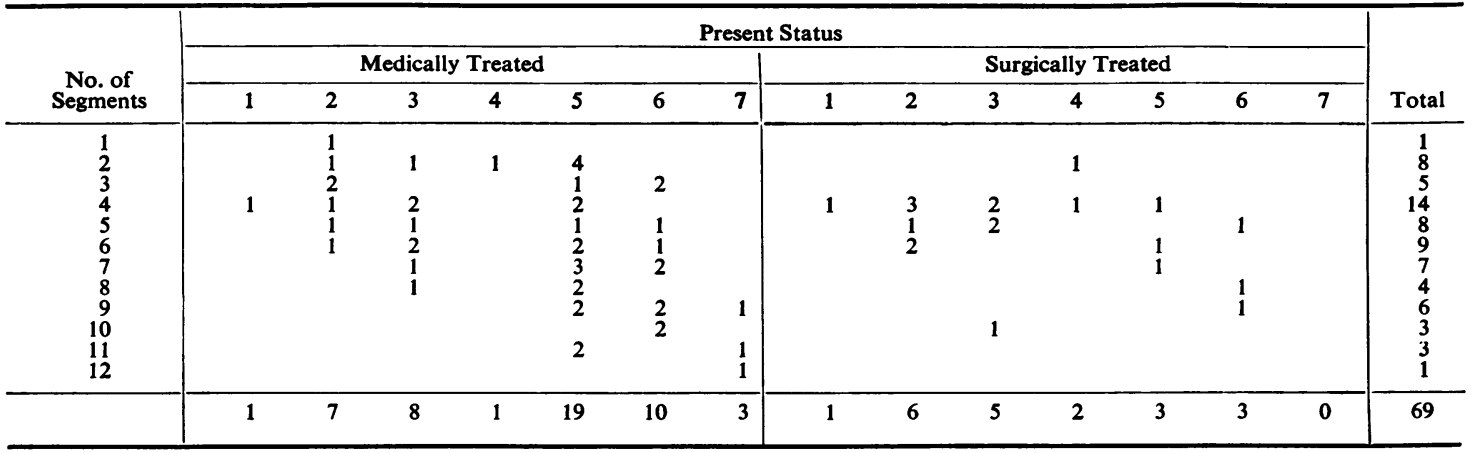

T A B L E IV

SPIROMETRY, Rresp AND LUNG VOLUMES

\begin{tabular}{|c|c|c|c|c|c|c|c|c|c|c|}
\hline & \multirow[b]{2}{*}{ Test } & \multirow[b]{2}{*}{ Treatment } & \multicolumn{8}{|c|}{ Number of Segments Involved } \\
\hline & & & Total & 1 & 2 & 3 & 4 & 5 & 6 & +7 \\
\hline \multirow{2}{*}{ VC } & $>80 \%$ predicted & $\begin{array}{l}\text { Medical } \\
\text { Surgical }\end{array}$ & $\begin{array}{l}41 \\
17\end{array}$ & 1 & $\begin{array}{l}6 \\
1\end{array}$ & 5 & $\begin{array}{l}4 \\
8\end{array}$ & $\begin{array}{l}4 \\
4\end{array}$ & $\begin{array}{l}5 \\
3\end{array}$ & $\begin{array}{r}16 \\
1\end{array}$ \\
\hline & $\begin{array}{l}<80 \% \text { predicted } \\
\text { Not done }\end{array}$ & $\begin{array}{l}\text { Medical } \\
\text { Surgical } \\
\text { Not done }\end{array}$ & $\begin{array}{l}\mathbf{6} \\
3 \\
2\end{array}$ & & 1 & & 2 & & 1 & $\begin{array}{l}2 \\
3 \\
2\end{array}$ \\
\hline \multirow{2}{*}{$\mathrm{FEV}_{1} / \mathrm{VC}$} & $>72 \%$ & $\begin{array}{l}\text { Medical } \\
\text { Surgical }\end{array}$ & $\begin{array}{l}35 \\
15\end{array}$ & 1 & 6 & 4 & $\begin{array}{l}5 \\
5\end{array}$ & $\begin{array}{l}4 \\
4\end{array}$ & $\begin{array}{l}5 \\
3\end{array}$ & $\begin{array}{r}10 \\
3\end{array}$ \\
\hline & $<72 \%$ & $\begin{array}{l}\text { Medical } \\
\text { Surgical } \\
\text { Not done }\end{array}$ & $\begin{array}{r}12 \\
5 \\
2\end{array}$ & & $\begin{array}{l}1 \\
1\end{array}$ & 1 & $\begin{array}{l}1 \\
3\end{array}$ & & 1 & $\begin{array}{l}8 \\
1 \\
2\end{array}$ \\
\hline \multirow{2}{*}{ Rresp. } & Normal & $\begin{array}{l}\text { Medical } \\
\text { Surgical }\end{array}$ & $\begin{array}{l}28 \\
11\end{array}$ & & $\begin{array}{l}4 \\
0\end{array}$ & 5 & $\begin{array}{l}4 \\
6\end{array}$ & $\begin{array}{l}\mathbf{0} \\
\mathbf{3}\end{array}$ & $\begin{array}{l}3 \\
2\end{array}$ & 12 \\
\hline & Increased & $\begin{array}{l}\text { Medical } \\
\text { Surgical } \\
\text { Not done }\end{array}$ & $\begin{array}{r}20 \\
9 \\
1\end{array}$ & 1 & $\begin{array}{l}3 \\
1\end{array}$ & & $\begin{array}{l}2 \\
2\end{array}$ & $\begin{array}{l}4 \\
1\end{array}$ & $\begin{array}{l}3 \\
1\end{array}$ & $\begin{array}{l}7 \\
4 \\
1\end{array}$ \\
\hline \multirow{3}{*}{ TLC } & $>120 \%$ predicted & $\begin{array}{l}\text { Medical } \\
\text { Surgical }\end{array}$ & $\begin{array}{r}16 \\
4\end{array}$ & 1 & $\begin{array}{l}3 \\
1\end{array}$ & 1 & $\begin{array}{l}1 \\
1\end{array}$ & $\begin{array}{l}1 \\
2\end{array}$ & 2 & 7 \\
\hline & $80-120 \%$ predicted & $\begin{array}{l}\text { Medical } \\
\text { Surgical }\end{array}$ & $\begin{array}{l}33 \\
15 \\
\end{array}$ & & 4 & 4 & $\begin{array}{l}5 \\
7\end{array}$ & $\begin{array}{l}3 \\
2\end{array}$ & $\begin{array}{l}4 \\
3\end{array}$ & $\begin{array}{r}13 \\
3\end{array}$ \\
\hline & $<80 \%$ predicted & $\begin{array}{l}\text { Medical } \\
\text { Surgical }\end{array}$ & $\begin{array}{l}0 \\
1\end{array}$ & & & & & & 1 & \\
\hline \multirow{2}{*}{ RV/TLC } & $<30 \%$ & $\begin{array}{l}\text { Medical } \\
\text { Surgical }\end{array}$ & $\begin{array}{l}34 \\
12 \\
\end{array}$ & 1 & $\begin{array}{l}6 \\
1\end{array}$ & 4 & $\begin{array}{l}4 \\
6\end{array}$ & $\begin{array}{l}4 \\
2\end{array}$ & $\begin{array}{l}4 \\
2\end{array}$ & $\begin{array}{r}11 \\
1\end{array}$ \\
\hline & $>30 \%$ & $\begin{array}{l}\text { Medical } \\
\text { Surgical }\end{array}$ & $\begin{array}{r}15 \\
8\end{array}$ & & 1 & 1 & 2 & 2 & $\begin{array}{l}2 \\
1\end{array}$ & $\begin{array}{l}9 \\
3\end{array}$ \\
\hline
\end{tabular}

patients had normal results predicted for two lungs. Ten of the medically treated patients with spirometric abnormalities had extensive disease with seven or more segments involved.

RESPIRATORY RESISTANCE Table IV also gives Rresp measurements for these patients. In 29 it was elevated but in nine, surgical resections may have contributed to the increase by reducing the airway number. Hence, there were 20 patients in whom there may have been extensive small airway disease or significant large airway narrowing due to structural abnormalities, mucosal changes or mucopus within the airway (Clarke, Jones, and Oliver, 1970).

LUNG VOLUMES The lung volumes in relation to the number of segments involved are given in Table IV. TLC was increased in 20 patients although greater than $140 \%$ predicted in only four. 
Four of the 20 were patients who had had resections. TLC was reduced below $80 \%$ predicted in only one patient who had extensive disease and resection of both right and left lower lobes. $\mathrm{RV} / \mathrm{TLC}$ ratio was increased in 23 patients and eight of these had been treated surgically.

MEFV CURVES Tables $\mathrm{V}$ and VI give shapes of MEFV curves, $V \max$ at $50 \%$ TLC, frequency dependence of Cdyn, and elastic recoil studies. Fourteen patients had very low Vmax (less than $0.20 \mathrm{TLC} / \mathrm{sec}$ ), eight treated medically and six surgically. Eight of these had curve types C, D, and $E$, five had curve type $B$, and one curve type A (normal) but this patient also had marked gas trapping and frequency dependence of Cdyn. Thirty-two patients had Vmax of 0.21 to 0.40 $\mathrm{TLC} / \mathrm{sec}$, and 19 of these had convex curves (types $\mathrm{C}$ and $\mathrm{D}$ ), five convexity low in the VC (type B), and eight curves type $A$ with frequency dependence of Cdyn. Twenty-three had normal Vmax. Six of these had convexity low in the VC (type B), 12 had curves type $A$ with frequency dependence of Cdyn, and four curves type $A$ without frequency dependence of Cdyn. One of these in whom no abnormality was found had both right middle lobe and left lobe resected.

ELASTIC RECOIL AND UPSTREAM CONDUCTANCE Eight patients (five treated medically and three surgically) had elastic recoil curves that were shifted up and to the left, indicating loss of recoil (Fig. 2). If the recoil curves were constructed with volume expressed as a percentage of predicted rather than of measured TLC as in Fig. 2, the curves of seven would be shifted further up as they had increased

T A B L E V

PATTERN OF MEFV CURVE RELATED TO Vंmax AT $50 \%$ TLC DOTTED LINE SEPARATES THE NORMALS

\begin{tabular}{|c|c|c|c|c|}
\hline \multirow[b]{2}{*}{ Pattern of MEFV Curve } & \multicolumn{4}{|c|}{$\dot{V} \max$ at $50 \%$ TLC } \\
\hline & $<0.20$ & $0.21-0.40$ & $>0.41$ & Total \\
\hline \multirow{5}{*}{$\begin{array}{l}\text { Biphasic } \\
\text { (curve type E) } \\
\text { Convex-uniform } \\
\text { (curve types C \& D) } \\
\text { Convexity low in VC } \\
\text { (curve type B) } \\
\text { Normal curve (type A) } \\
\text { with increased } \\
\text { RV and frequency } \\
\text { dependency of Cdyn } \\
\text { Normal curve (type A) } \\
\text { with frequency } \\
\text { dependence of Cdyn }\end{array}$} & 1 & & & 1 \\
\hline & 7 & 19 & 0 & 26 \\
\hline & 5 & 5 & 6 & 16 \\
\hline & 1 & 5 & 2 & 8 \\
\hline & $\mathbf{0}$ & 3 & 10 & 13 \\
\hline $\begin{array}{c}\text { Normal curve (type A) } \\
\text { without frequency } \\
\text { dependence of Cdyn }\end{array}$ & 0 & o & 5 & 5 \\
\hline Total & 14 & 32 & 23 & 69 \\
\hline
\end{tabular}

(a)

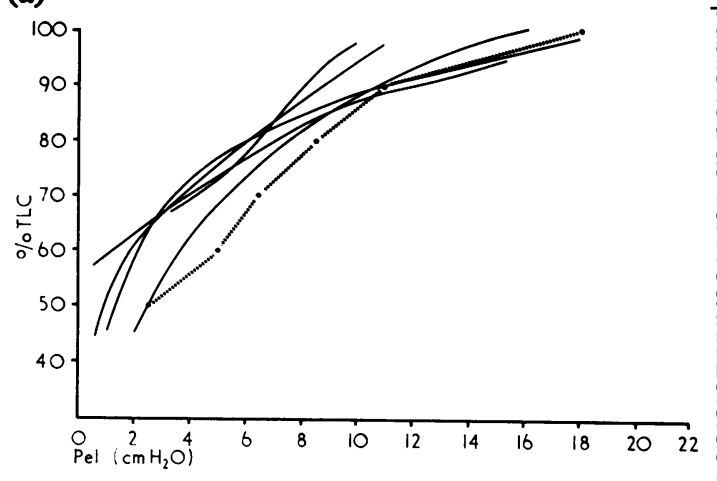

(b)

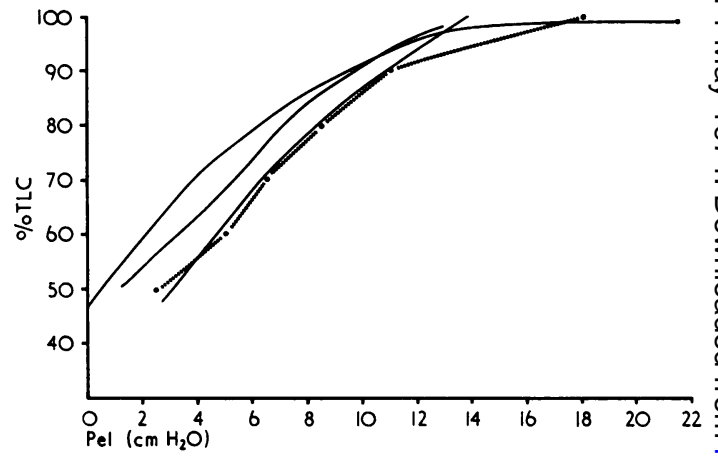

FIG. 2. Static elastic recoil curves in the eight? patients with impaired recoil: (a) medically treated patients; (b) surgically treated patients. The limit of normality is indicated by the broken line.

TLC, but the slope would not be greatly altered. Table VI gives details of elastic recoil pressure at $\delta$ TLC. The surgically treated patients with loss of recoil had resections of the left lower lobe in two o cases and left lower lobe and lingula in one at the ages of 12, 15, and 23 years respectively. The alterations in elastic recoil indicated that there may have been some emphysematous changes in $\mathrm{N}$ these eight patients though the displacement of 0 the recoil curve was less than that seen in patients N with widespread emphysema (Finucane and Colebatch, 1969).

Gus was calculated at FRC and the results are shown in Table VI. Gus was below normal in 35 patients. Twelve of these had been treated surgi- cally and the normal value for two lungs may not ${ }^{\circ}$ be applicable. Five of the 35 patients had low $\overrightarrow{\mathbb{D}}$ recoil and low Gus and may have both airway obstruction and emphysema contributing to the
reduction in Vmax.

Fifteen patients had a reduced $\nabla \max$ and $\delta$ 
T A B L E VI

Vंmax AT $50 \%$ TLC, UPSTREAM CONDUCTANCE, FREQUENCY DEPENDENCE OF Cdyn, AND RECOIL PRESSURE AT TLC

\begin{tabular}{|c|c|c|c|c|c|c|c|c|c|}
\hline \multirow[b]{2}{*}{$\begin{array}{l}\dot{V} \max \\
\text { TLC50 }\end{array}$} & \multicolumn{2}{|c|}{ Treatment } & \multicolumn{2}{|c|}{ Gus } & \multicolumn{3}{|c|}{ Frequency Dependence Cdyn } & \multicolumn{2}{|c|}{ Pel at TLC } \\
\hline & Type & No. & Normal & Low & Present & Absent & Unsatisfactory & $<20$ & $\left(\mathrm{cmH}_{2} \mathrm{O}\right)^{>20}$ \\
\hline$<0 \cdot 20$ & $\begin{array}{l}\text { Medical } \\
\text { Surgical }\end{array}$ & $\begin{array}{l}8 \\
6\end{array}$ & 1 & $\begin{array}{l}7 \\
5\end{array}$ & $\begin{array}{l}8 \\
6\end{array}$ & & & $\begin{array}{l}2 \\
1\end{array}$ & $\begin{array}{l}6 \\
5\end{array}$ \\
\hline $0.21-0.40$ & $\begin{array}{l}\text { Medical } \\
\text { Surgical }\end{array}$ & $\begin{array}{r}27 \\
5\end{array}$ & $\begin{array}{r}12 \\
1\end{array}$ & $\begin{array}{r}15 \\
4\end{array}$ & $\begin{array}{r}23 \\
5\end{array}$ & 2 & 2 & $\begin{array}{l}6 \\
1\end{array}$ & 21 \\
\hline$>0.41$ & $\begin{array}{l}\text { Medical } \\
\text { Surgical }\end{array}$ & $\begin{array}{r}14 \\
9\end{array}$ & 12 & 2 & 11 & $\begin{array}{l}3 \\
1\end{array}$ & 2 & 2 & $\begin{array}{r}12 \\
8\end{array}$ \\
\hline
\end{tabular}

normal Gus but the MEFV curve pattern in eight of these had a slight convexity low in vital capacity and they may have localized disease. Normally a reduced Vmax in the presence of normal Gus suggests that the reduction in Vmax is due to loss of elastic recoil; however, the normal recoil studies and the pattern of MEFV curves in these eight patients suggest either very mild small airway disease or slow emptying from an area of localized disease. Three of the patients with decreased Vmax and normal Gus had low recoil pressures, suggesting that loss of elastic recoil contributed to the low Vmax. The remaining 19 patients had normal Gus and Vmax.

\section{DISCUSSION}

In bronchiectasis, obliteration of bronchioles and destruction of bronchial walls has been demonstrated pathologically (Whitwell, 1952) but the understanding of the functional effects of these changes has been limited by the precision of methods used for evaluating the disease. Studies of the mechanics of ventilation have created an opportunity for comprehensive evaluation of these lesions. In this study, the present status of the patients varied, 28 patients having intermittent symptoms and 41 persistent cough and sputum. As in most other series (Diamond and van Loon, 1942; Field, 1949; Strang, 1956; Williams and O'Reilly, 1959), the disease process began in the majority of patients under 5 years of age.

Forty-nine were treated medically and 20 surgically. Interpretation of the present status in relation to treatment is limited as the populations were biased by selection. However, six out of nine treated surgically where the disease process was localized have been relieved of their symptoms, whereas in patients with extensive disease, there was no significant difference between those treated medically or surgically. Twenty-eight of the 69 patients no longer have chronic cough, which is very similar to the $33 \%$ subsidence of this symptom reported by Field (1961).

Approximately one-third of the patients showed an abnormality on routine spirometric tests and most of these had other evidence of extensive disease. This is much smaller than reported previously (Smith, Siebens, and Story, 1954; Cherniak et al., 1959; Strang, 1960; Pande et al., 1971) and suggests that this study included milder cases; it may also reflect the natural improvement seen during adolescence (Field, 1961). Spirometric tests were not of value in grading disease nor in detecting persisting mild abnormalities.

Twenty-nine patients with extensive disease had an elevated Rresp. This compares with 23 out of 31 with elevated Rpulm in the series by Pande et al. (1971). Their patients had more active and more widespread disease than those in the present series.

TLC was increased in 20 patients, which is comparable to that reported in previous studies (Smith et al., 1954). The RV/TLC ratio was increased in 23 patients, of whom eight were treated surgically. The higher incidence of an elevated RV/TLC ratio in this study compared with other reports (Etsten, Overholt, Walker, and Reynolds, 1953; Peters et al., 1950) could be related to the use of the plethysmograph for determining lung volumes as this measured trapped gas not detected by the gas dilution techniques. The elevated RV probably resulted from airways closure at an abnormally high lung volume caused by residual airway disease.

Analysis of the MEFV curves suggested a number of different patterns of disease and there was no significant difference between the curves seen in those treated medically and those treated surgically although Vmax tended to be a little slower in those who had resections. The patterns seen in this study were:

1. Generalized convexity of the MEFV curve usually with reduced Vmax, hyperinflation, and in 
severe cases increased Rresp and abnormal spirometry. This is suggestive of moderate to severe generalized airway obstruction. One patient had a biphasic curve which may indicate severe airway obstruction with or without increased collapsibility of large airways (Mead et al., 1967).

2. Those with convexity low in the VC usually with reduced Gus and frequency dependence of Cdyn. In some normal young adults a slight convexity to the $\mathrm{x}$-axis near RV may be normal, but in the present study, only one patient with this shaped curve did not have frequency dependence of Cdyn. Hence, the change in slope near RV is likely to be related to some pathological process. There may have been minor generalized small airways disease causing reduced Vmax at low lung volumes only or alternatively localized disease. Bass $e t$ al. (1968) have shown hypoventilation of bronchographically normal areas adjacent to bronchiectatic regions using xenon-133. Procedures used in the present study would not allow separation of these possible causes.

3. Normal curves and normal elastic recoil with frequency dependence of Cdyn would suggest the presence of mild small airway disease.

4. Normal shaped curves with increased RV may be due to locally trapped air which is not expelled during a forced vital capacity manoeuvre, possibly due to compliant bronchi in the diseased segments. In this study, its presence was suggested by frequency dependence of Cdyn in all and reduced Vmax in six of the eight patients with this pattern.

5. The final group with normal MEFV curves and no other abnormality on other tests performed must be considered free of persisting disease.

There have been no previous reports of MEFV curves in patients with bronchiectasis. The convex MEFV curves in association with reduced Vmax and Gus as well as frequency dependence of Cdyn confirms the likely presence of generalized small airway disease. These would be similar to the follicular group described by Whitwell (1952) in which widespread bronchiolar occlusion was noted. This group may also equate with those described by Fraser, Macklem, and Brown (1965), in whom a reduction in calibre of major bronchi and bronchiectatic segments was noted during forced expiration. With small airway obstruction, the EPP would move rapidly upstream and widespread secondary dynamic compression and flow limitation, especially low in the VC, would occur.

Some patients showed abnormalities that would be consistent with compliant airways in the bronchiectatic segment, producing either change in slope of the MEFV curve low in the VC or gas trapping. This change would be equivalent to that $\stackrel{5}{\rightarrow}$ reported by Fraser et al. (1965) in the group with marked reduction in calibre of the major bronchi $\overline{\bar{\sigma}}$ but not the bronchiectatic segment. In these $\frac{\bar{s}}{7}$ patients with compliant airways, the EPP would $\stackrel{\varnothing}{\varnothing}$ stop moving upstream so that the bronchiectatic segment would be upstream and therefore remain $\vec{\circ}$

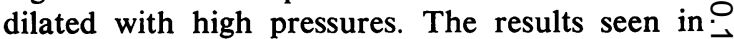
these patients were not those reported in $\vec{\omega}$ generalized bronchomalacia with bronchiectasis $\%$ (Williams, Landau, and Phelan, 1972).

Cherniak and Carton (1966) and Pande et al. (1971) found reduced Cdyn in about $30 \%$ of the $\dot{\omega}$ patients they studied, and Pande et al. (1971) $\dot{\omega}$ suggested this was probably due to fibrosis. How- + ever, this present study suggests that any reduction 은 in Cdyn is more likely to be due to maldistribution of ventilation from persisting generalized smalls airway disease. The four patients with reduced $\ll$ Vmax but normal Gus with reduced recoil may $\vec{\omega}$ have loss of supporting tissue contributing to the flow limitation. The tests used could not determine whether this would be localized or generalized pathology. Widespread emphysema did not appear to be present in any patient.

The study has shown that following resection $\frac{0}{\circ}$ of one or two lobes in childhood, TLC, VC, and $\stackrel{\varrho}{=}$ pulmonary mechanics measured in the remainingo을 lung tissue may be within normal predicted limits for two lungs. One patient had a completely normal study following right middle lobe and left $\mathrm{-}$ lower lobe resections. Abnormalities in patients who had resections were probably the result of persisting disease (Cook and Bucci, 1961; Foster, Jacobs, and Daniel. 1961).

\section{CONCLUSION}

Detailed studies of the mechanics of ventilation? have been carried out in 69 patients with bronchi-o ectasis. The clinical features in this group of patients with long-term follow-up was in agreement with previous reports (Field, 1969; Strang, N 1956), many patients remaining well with minimaN disability and a marked tendency to improve $\omega$ during adolescence. Although many had persistent cough and sputum they were still functioninge very well and missing very few days work with nos other disability or limitation of their activities The relatively good pulmonary function reflected 5 their clinical status.

This study indicates that generalized small air $\frac{}{\mathrm{D}}$ way disease is common in patients with bronchiectasis as suggested by pathological studies and some previous investigations of pulmonary func? 
tion (Moore, Kobernick, and Wiglesworth, 1949; Cherniak and Carton, 1966). The MEFV curve proved the most useful and sensitive practical test to detect this, and a number of different patterns of disease have been related to the changes in the MEFV curves.

In those treated surgically, postoperative function depended on the extent of persisting disease rather than on the resection itself.

We acknowledge the assistance of Miss. E. Coombs, S.R.N., and Miss J. Joel in carrying out the respiratory function tests. We also thank Mr. R. N. Howard and Mr. N. A. Myers for allowing us to study their patients who had resections.

\section{REFERENCES}

Bass, H., Henderson, J. A. M., Heckscher, T., Oriol, A., and Anthonisen, N. R. (1968). Regional structure and function in bronchiectasis. American Review of Respiratory Disease, 97, 598.

Birath, G., Crafoord, C., and Rudström, P. (1947). Pulmonary function after pneumonectomy and lobectomy. Journal of Thoracic Surgery, 16, 492.

Cherniak, N. S. and Carton, R. W. (1966). Factors associated with respiratory insufficiency in bronchiectasis. American Journal of Medicine, 41, 562.

- Vosti, K. L., Saxton, G. A., Lepper, M. H., and Dowling, H. F. (1959). Pulmonary function tests in fifty patients with bronchiectasis. Journal of Laboratory and Clinical Medicine, 53, 693.

Clarke, S. W., Jones, J. G., and Oliver, D. R. (1970). Resistance to two-phase gas-liquid flow in airways. Journal of Applied Physiology, 29, 464.

Cook, C. D. and Bucci, G. (1961). Studies of respiratory physiology in children: The late effects of lobectomy on pulmonary function. Pediatrics, 28, 234.

Diamond, S. and van Loon, E. L. (1942). Bronchiectasis in childhood. Journal of the American Medical Association, 118, 771.

Du Bois, A. B., Botelho, S. Y., Bedell, G. N., Marshall, R., and Comroe, J. H. Jr. (1956a). A rapid plethysmographic method for measuring thoracic gas volume; comparison with a nitrogen washout method for measuring functional residual capacity in normal subjects. Journal of Clinical Investigation, 35, 322.

, Brody, A. W., Lewis, D. H., and Burgess, B. F. Jr. (1956b). Oscillation mechanics of lungs and chest in man. Journal of Applied Physiology, 8, 587.

Etsten, B. E., Overholt, R. H., Walker, J. H., and Reynolds, R.N. (1953). Pulmonary function after segmental pulmonary resection for bronchiectasis. New England Journal of Medicine, 248, 81.

Field, C. E. (1949). Bronchiectasis in childhood: II. Aetiology and pathogenesis, including a survey of 272 cases of doubtful irreversible bronchiectasis. Pediatrics, 4, 231.
(1961). Bronchiectasis: A long-term follow-up of medical and surgical cases from childhood. Archives of Diseases in Childhood, 36, 587.

(1969). Bronchiectasis: Third report on a followup study of medical and surgical cases from childhood. Archives of Disease in Childhood, 44, 551.

Filler, J., Gomez, D. M., and Stone, S. (1966). Effects upon pulmonary function of pneumonectomy performed during childhood. American Review of Respiratory Disease, 93, 184.

Finucane, K. E. and Colebatch, H. J. H. (1969). Elastic behaviour of the lung in patients with airway obstruction. Journal of Applied Physiology, 26, 330.

Foster, J. H., Jacobs, J. K., and Daniel, R. A. (1961). Pulmonary resection in infancy and childhood. Annals of Surgery, 153, 658.

Fraser, R. G., Macklem, P. T., and Brown, W. G. (1965). Airway dynamics in bronchiectasis. American Journal of Roentgenology, 93, 821.

Grimby, G., Takishima, T., Graham, W., Macklem, P. T., and Mead, J. (1968). Frequency dependence of flow resistance in patients with obstructive lung disease. Journal of Clinical Investigation, 74, 1455.

Hyatt, R. E., Schilder, D. P., and Fry, D. L. (1958). Relationship between maximum expiratory flow and degree of lung inflation. Journal of Applied Physiology, 13, 331.

Kamener, R., Becklake, M. R., Goldman, H., and McGregor, M. (1958). Respiratory function following segmental resection of the lung for bronchiectasis. American Review of Tuberculosis, 77, 209.

Landau, L. I. and Phelan, P. D. (1973). Evaluation of two techniques for measurement of respiratory resistance by forced oscillation. Thorax, 28, 136.

Lester, C. W., Cournand, A., and Riley, R. L. (1942). Pulmonary function after pneumonectomy in children. Journal of Thoracic Surgery, 11, 529.

Mcllroy, M. B. and Bates, D. V. (1956). Respiratory function after pneumonectomy. Thorax, 11, 303.

Macklem, P. T. (1971). Airway obstruction and collateral ventilation. Physiological Reviews, 51, 368.

and Mead, J. (1967). Resistance of central and peripheral airways measured by a retrograde catheter. Journal of Applied Physiology, 22, 395.

Mead, J., Turner, J. M., Macklem, P. T., and Little, J. B. (1967). Significance of the relationship between lung recoil and maximum expiratory flow. Journal of Applied Physiology, 22, 95.

Milic-Emili, J., Mead, J., Turner, J. M., and Glauser, E. M. (1964). Improved technique for estimating pleural pressure from esophageal balloons. Journal of Applied Physiology, 19, 207.

Moore, J. R., Kobernick, S. D., and Wiglesworth, F. W. (1949). Bronchiectasis: a study of the segmental distribution of the pathological lesions. Surgery, Gynecology and Obstetrics, 89, 145.

Otis, A. B., McKerrow, C. B., Bartlett, R. A., Mead, J., McIlroy, M. B., Selverstone, N. J., and Radford, E. P. Jr. (1956). Mechanical factors in distribution of pulmonary ventilation. Journal of Applied Physiology, 8, 427. 
Pande, J. N., Jain, B. P., Gupta, R. G., and Guleria, J. S. (1971). Pulmonary ventilation and gas exchange in bronchiectasis. Thorax, 26, 727.

Peters, R. M., Roos, A., Black, H., Burford, T. H., and Graham, E. A. (1950). Respiratory and circulatory studies after pneumonectomy in childhood. Journal of Thoracic Surgery, 20, 484.

Polgar, G. and Promadhat, V. (1971). Pulmonary Function Testing in Children, p. 87. Saunders, Philadelphia.

Smith, G. A., Siebens, A. A., and Storey, C. F. (1954). Preoperative and postoperative cardiopulmonary function studies in patients with bronchiectasis. American Review of Tuberculosis, 69, 869.

Strang, C. (1956). The fate of children with bronchiectasis. Annals of Internal Medicine, 44, 630.

Strang, L. B. (1960). Abnormalities of ventilatory capacity in children with asthma and bronchiectasis. Archives of Diseases in Childhood, 35, 224.

Turner, J. M., Mead, J., and Wohl, M. E. (1968). Elasticity of human lungs in relation to age. Journal of Applied Physiology, 25, 664.
Whitwell, F. (1952). A study of the pathology and pathogenesis of bronchiectasis. Thorax, 7, 213.

Williams, H. E., Landau, L. I., and Phelan, P. D. (1972). Generalized bronchiectasis due to exten- $\overline{\bar{S}}$ sive deficiency of bronchial cartilage. Archives of $\vec{\Phi}$ Diseases in Childhood, 47, 423.

and O'Reilly, R.N. (1959). Bronchiectasis in के children: its multiple clinical and pathological $\vec{\circ}$ aspects. Archives of Diseases in Childhood, 34, 192.

Woolcock, A. J., Vincent, N. J., and Macklem, P. T. (1969). Frequency dependence of compliance as a test for obstruction in the small airways. Journal of Clinical Investigation, 48, 1097.

Zapletal, A., Motoyama, E. K., van de Woestijne, $\omega$ K. P., Hunt, V. R., and Bouhuys, A. (1969). Maximum expiratory flow-volume curves and air- $\perp$ way conductance in children and adolescents: Journal of Applied Physiology, 26, 308.

Requests for reprints to: Dr. P. D. Phelan, Royal Children's Hospital, Flemington Road, Parkville 3052, Australia. 